\title{
The influence of cranio-cervical rehabilitation in patients with myofascial temporomandibular pain disorders
}

\author{
Halmova K, Holly D, Stanko P \\ Department of Stomatology and Maxillofacial Surgery, Faculty of Medicine, Comenius University and St. Elizabeth \\ Institute of Oncology, Bratislava, Slovakia. kristina.halmova@ousa.sk
}

\begin{abstract}
OBJECTIVE: The aim of the study was to prove the causality between the craniocervical dysfunction and myofascial pain in the head and neck and to demonstrate the clinical value and usefulness of physiotherapy as one of the therapeutic options for myofascial pain.

METHODS: The group of patients diagnosed with myofascial dysfunctional pain syndrome contained 98 patients out of which 79 patients $(81 \%)$ were females and 19 patients $(19 \%)$ were males. The majority of the patients were aged between 26 and 35 years; the total age range was 14-77 years with the average of 38 years. Observed patients were subdivided into three groups. Standard therapeutic methods aimed at the temporomandibular joint were provided to the patients of the first group. The second group of the patients received therapy aimed at cervical muscles only. Complex rehabilitation was applied in the third group of patients. The most frequent method used in the evaluation of chronic musculoskeletal pain in clinical studies is the visual analogue scale (VAS).

RESULTS: According to our results, all three groups of patients saw an improvement in pain perception, but the overall subjective remission of painful sensations in the third group took place in as many as $88 \%$ of patients. In this group, there was a significant decrease in the tenderness of trigger points in the trapezius and sternocleidomastoid muscles.

CONCLUSION: It was proved that a combination of simple relaxing and stretching exercises of cervical muscles with a standard method used in the therapy of masticatory muscles is significantly more efficient (Fig. 5, Ref. 18). Text in PDF www.elis.sk.

KEY WORDS: temporomandibular disorders, cervicocranial dysfunction, myofascial pain.
\end{abstract}

\section{Introduction}

A high proportion of population suffers from some level of temporomandibular joint disorder and as it has multifactorial etiology and the proportion of the psycho-emotional influences is high, it can be expected that the number of patients suffering from one of the temporomandibular disorders (TMDs) will increase.

TMDs are characterized by three basic signs: temporomandibular joint pain, decrease in the mandibular motility, and audible phenomena.

It needs to be pointed out that the pain in masticatory and cervical spine muscles is of myofascial origin and it is very common among today's society. The most common cause of TMD is the myofascial pain itself. Wrong body position in combination with spinal root compression and implicated prolonged isometric contraction of the muscles and other degenerative changes in ten-

Department of Stomatology and Maxillofacial Surgery, Faculty of Medicine, Comenius University and St. Elizabeth Institute of Oncology, Bratislava, Slovakia

Address for correspondence: K. Halmova, MD, MPH, Department of Stomatology and Maxillofacial Surgery, Faculty of Medicine, Comenius University and St. Elisabeth Institute of Oncology, Heydukova 10, SK81250 Bratislava, Slovakia.

Phone: $+421.2 .32249735,+421.911541891$ dons and ligaments are the most important etiologic factors of the disorder. The formation of myofascial pain in the head and neck is significantly influenced by hyperextension of the upper cervical spine (C1-C3) and flexion of its lower part (C4-C7). Hyperlordosis of the $\mathrm{C}$ spine implicates anteflexion position of the head, and hyperkyphosis of Th spine (compensating hyperlordosis of $\mathrm{C}$ and L parts of the spine) leads to anteflexion position of the shoulders. The early diagnosis is crucial in order to prevent the deterioration and formation of chronic pain with all its psychosocial and functional consequences and development of fibromyalgia. Unfortunately, in clinical practice, these pains are often neglected.

As there is no golden standard therapy aimed at TMDs, the reversible non-invasive therapeutic modalities are preferred. One of the most efficient non-invasive therapeutic methods is physiotherapy, especially exercises and mobilization of the temporomandibular joint (TMJ). Even though there is no sufficient evidence of causality with craniocervical dysfunction, it is recommended to include this area into complex physiotherapy.

Right diagnosis and therapy of the myofascial pain calls for multidisciplinary approach and with regards to that physiotherapy has an important role in the search for the correct therapeutic modality. Craniocervical and orofacial pain is treated with success in cooperation with physiotherapists. It is crucial to set an individual plan for complex rehabilitation for every patient with the use of 
manual and physical therapy aimed not only at TMJ, but also at the body as a whole, right posture of the head and body, as well as at the removal of trigger points (TrPs).

In the group of patients observed in our clinic between 2012 2014 , the proved causality was between cervicocranial dysfunction and myofascial pain in the area of the head and neck, and the clinical value and usefulness of the physical therapy as one of the therapeutic modalities of treatment of myofascial pain was confirmed.

\section{Materials and methods}

In order to collect relevant data, all patients diagnosed with myofascial disease pain syndrome (MDPS) examined at the Department of Stomatology and Maxillofacial Surgery Faculty of Medicine, Comenius University and St. Elizabeth Institute of Oncology in Bratislava from January 2012 to January 2014 were included in the study. In this period, there were 133 patients diagnosed with temporomandibular joint disorder. Patients with confirmed X-ray changes in open and closed mouth positions and patients with general inflammatory diseases were excluded from the study. The total number of patients with the diagnosis of MDPS was 98, out of which 79 (81\%) were females and 19 (19\%) males. The majority of the patients were aged between 26

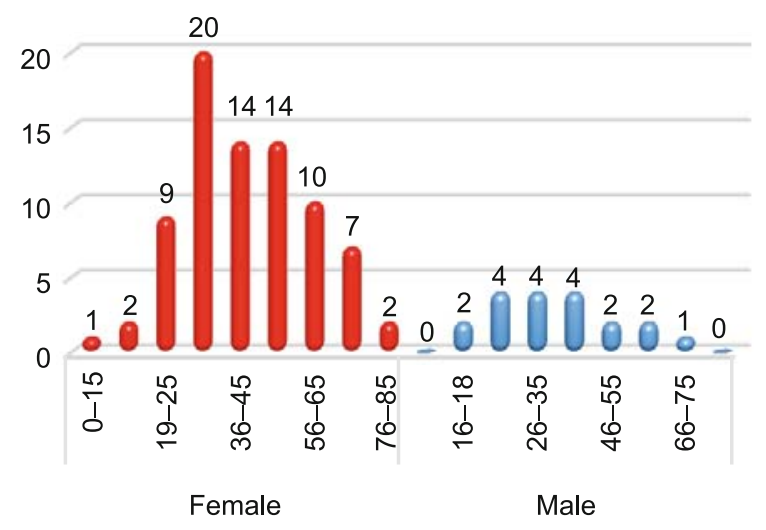

Fig. 1. Division of the patients into groups by age.

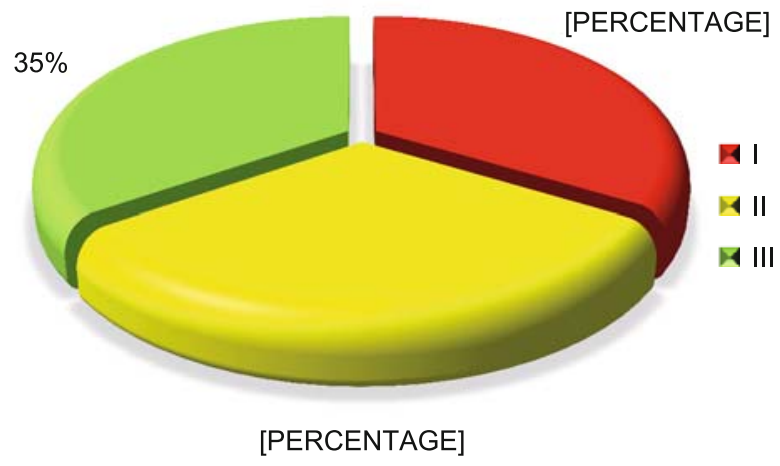

Fig. 2 Proportion of the patients in the therapeutic groups.

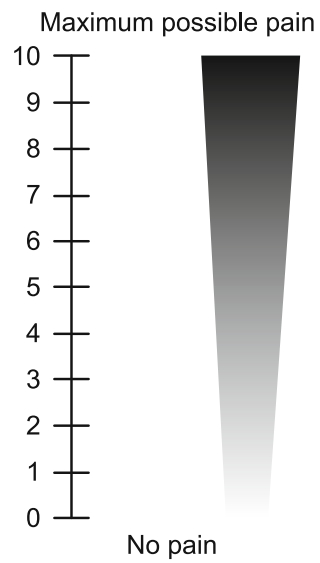

Fig. 3. Visual Analogue Scale.

and 35 years, total age range was $14-77$ years with the average of 38 years (Fig. 1).

The patients were divided into three groups.

The first group consisted of patients treated with standard methods aimed at the area of TMJ provided in ambulatory setting: rest, analgesics, myorelaxing agents, splint therapy and Schulte's exercises. There were 33 patients (34\%) participating in this group.

In the second group, the therapy provided was aimed exclusively at cervical spine muscles. Patients received instructions from our rehabilitation center, focused on the most impacted muscles according to palpation examination. There were 31 (31\%) participants in this group.

The third group of patients consisted of 34 patients (35\%), and underwent complex rehabilitation with the use of physical and manual therapy, focused not only on TM joint, but on the body as a whole, right posture of the head and body as well as on removal of $\operatorname{TrP}$ (Fig. 2).

Considering that pain is one of the most frequent reasons for visiting the healthcare facilities $(1,2)$, the quantification of pain relief is a common tool in evaluating the results and efficiency of TM disorders therapy. The visual analogue scale is the most widely used method in evaluation of chronic musculoskeletal pain in clinical studies. VAS is targeted on the measurement of one component only; it is easy and fast to fill the form and not disturbing for the patient. A study from Germany by Piekartz and Ludtke (2011) (3) evaluates the efficacy of TMDs and cervical muscles therapy by measuring the craniofacial pain intensity using the colored VAS (Fig. 3).

The presence and location of TrP was examined by palpation in each group. There is no normative evaluation for muscular tonus using this method. In our group of patients, subjective pain sensations during palpation were measured using the VAS before and after the therapy.

An X-ray of cervicocranial spine was made for all the patients in sagittal and anteroposterior projection based on Harrison's study (4) describing four basic configurations of cervical spine in sagittal projection. 


\section{Results}

Based on X-ray imaging, the problem was recorded in 20 patients in the first group, which stands for $60.6 \%$ of that group. 64.5 $\%$ of patients in the second group and $58.8 \%$ of patients in the third group had positive X-ray findings (Fig. 4). The overall positive Xray finding was in $61.2 \%$ of all the patients with males prevailing.

The presence of $\operatorname{TrP}$ in selected muscles before therapy was as follows: $54.1 \%$ (53 patients) in the masseter muscle (MM), 63.5 $\%$ in the trapezius muscle (MT) and $65.3 \%$ in the lateral pterygoid muscle (MPTL), showing no statistically significant differences according to $\chi 2$-test. $\operatorname{TrP}$ were present in the sternocleidomastoid muscle (MSCM) in $75.5 \%$ of patients before the therapy.

The overall presence of TrP after the therapy was in $44.9 \%$ (44 patients) in MM. There was a decrease in palpation tenderness from $54.5 \%$ to $36.4 \%$ in the first group, and from $54.8 \%$ to $45.2 \%$ in the second group. In the third group, the palpation tenderness of $\operatorname{TrP}$ in MM remained at the same level of $52.9 \%$ after the therapy.

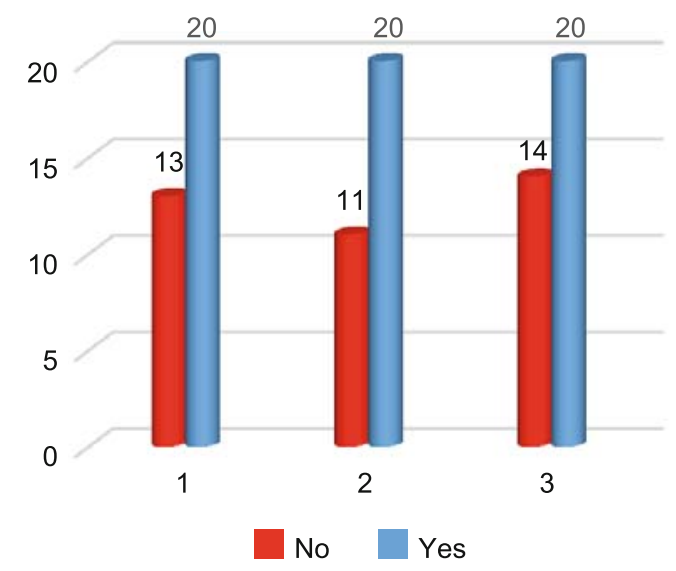

Fig. 4. X-ray findings of the patients in different groups.

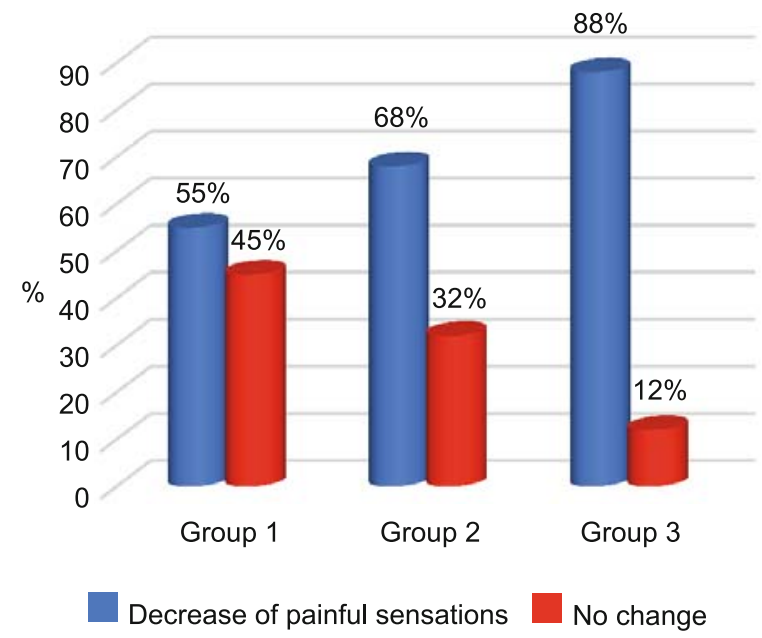

Fig. 5. Comparison of tenderness in the different groups of patients.
The overall presence of TrP in MT was reported in 55.1\% of patients. There was no change in the first group; a decrease in palpation tenderness in the second group from $67.7 \%$ (21) to 54.8 $\%$ (17), and from $58.8 \%$ (20) to $41.2 \%$ (14) in the third group.

The palpation tenderness for MPTL decreased from $69.7 \%$ (23) to $33.3 \%$ (11) in the first group. In the second group, there was an increase from $67.7 \%(21)$ to $71 \%(22)$. In the third group, the tenderness decreased from $58.8 \%$ (20) to $50 \%$ (17).

Palpation tenderness of MSCM decreased in total of $60.2 \%$ of treated patients with normal distribution.

Painful sensations of selected muscles were evaluated using VAS before and after the therapy in all groups. According to our results, all three groups reported an improvement, but the overall subjective decrease in pain was reported in as many as $88 \%$ of patients in the third group. There was a significant drop in the occurrence of tenderness of TrPs in the trapezius and sternocleidomastoid muscles in this group when compared to other two groups. In the first and second groups, the relief from pain was reported in $54.55 \%$ and $67.74 \%$, respectively (Fig. 5).

\section{Discussion}

There are several opinions regarding the prevalence of TM disorders; some authors give numbers as high as $60-70 \%$ of population $(5,6)$. There is a higher proportion of women suffering from this condition according to authors $(7,8)$. In the last studies, it is reasoned by women's higher sensitivity and by the fact that women are visiting the healthcare facilities more often than men. Up to $80 \%$ of muscular pains in the area of TMJ are caused by muscle pathology $(9,10)$.

TrPs are formed at the level of muscle fibers as a consequence of hypertonus from misbalanced muscle coordination. Misbalance in the craniocervical part changes the movement strategy which is no longer optimal for certain movements because of the weakening of profound flexors of the neck participating in stabilization of the cervical spine. Their deteriorated function is changing the right position of cervical spine. It all results in an increased tonus of neck extensors and implies the anteflexion of the head. This provokes the nociceptive impulses which imply the activation of non-coordinated stabilizing muscles of the cervical spine. The result of all these is the sensation of pain and the fact that the patient is no longer able to perform the movement in a correct way. The TrPs are being formed in wrongly used muscles and the pain irradiates further on. As a consequence of functional changes in muscles, joint blockages are formed, which are automatically immobilizing a certain segment and limiting the range of motion. There is an increased activity of superficial muscles (e.g. sternocleidomastoid muscle), which are also supporting respiration, and in case of an incorrect habit of upper type of respiration they contribute to increased functional misbalance. The presence of trigger points in MSCM and their relation to cervicocranial dysfunctions was already documented by Lewit (11). The mutual functional connection of the head and jaw, as two segments connected by joint to the cervical spine, influences the position of head and muscle connections influencing these 
segments or passing through this area. A wrong posture of masticatory muscles overloads the sternocleidomastoid muscle and its role in joint stability and the latter muscle frequently impacts the structure of cervical spine (12). A long-term cervical dysfunction can influence the function of masticatory muscles and TMJ and vice versa $(13,14)$.

Rehabilitation is one of the most frequently used modalities of conservative therapy of TMDs. Exercises and education about correct performance of these exercises was more efficient than splint therapy when focused on muscular pain relief in patients with TM disorders (15).

The aim of physiotherapy is to diminish the pain and to improve joint function in term of increasing the range of motion. There are many studies describing the effect of physiotherapy but only few randomized clinical trials. In case of signs of pain, relaxing and stretching exercises should be a part of first choice treatment. They have an effect on circulation, improve the flexibility and range of motion, and decrease the pain (16). The exercises focused on coordination help to improve the muscle function, motility and synchronization of jaw movements. The terms relaxing, stretching and coordination exercises, manual therapy, therapeutic exercises etc. are too wide while exact types of exercises, modes of their performance, and frequency and number of repetition need to be precise. The best results are achieved using multidisciplinary approach aimed at pain relief and muscle coordination and strength (17).

The results of our study prove that dysfunction of TM joint and craniocervical spine are connected and that complex therapy of masticatory muscles and cervical muscles is needed. The complexity of interactions between TM joint and cervical spine makes the identification of the origin of pain difficult (18) and non-complex therapy can lead to therapeutic failure.

\section{Conclusion}

There are many sources and studies trying to prove the connection between body posture, cervicocranial spine and TM joint in available databases, but the majority of them are not sufficiently relevant. Though it is difficult to define variables, consideration should be given to functional links in the head as well as functional bonds of other structures of the locomotor system and to admit muscle chaining. The problem is very complex and influenced by many reactions at an internal level of organism.

MDPS, as the most frequent disease of TM joint, does not have a clear therapeutic approach. The treatment of choice is conservative therapy. This offers many options of approaches, methods and concepts of rehabilitation, exercises, manual and physical therapy. Scientific evidence proving the efficiency of certain selected concepts are missing. In these terms, the individual approach to every patient is more important than a strict follow-up of either one of the methods. By this study we have proved a significant efficiency of simple relaxing and stretching exercises of cervical muscles in combination with the widely used masticatory muscles therapy. There is also a necessity of rehabilitation of the cervicocranial spine in order to achieve successful therapy of MDPS.

\section{References}

1. Dworkin RH et al. Interpreting the clinical importance of treatment outcomes in chronic pain clinical trials. IMMPACT recommendations. J Pain 2008; 9 (2): 105-121.

2. Okeson JP. Managment of Temporomandibular Disorders and Occlusion. St. Luis: Mosby Year book, 1993: 624.

3. Piekartz H, Ludtke K. Effect of treatment of temporomandibular disorders (TMD) in patients with cervicogenic headache: a single-blind, randomized controlled study. J Craniomandibular Pract 2011; 29 (1): 43-56.

4. Harrison DE, Harrison DD, Janik TJ et al. Comparison of axial and flexural stresses in lordosis and three buckled configurations of the cervical spine. Clin Biomech2001: 16 (4): 276-284.

5. Kotrán̆ M, Kysel' M, Kártik P. Poruchy mobility sánky a auskultačné fenomény. Vybrané kapitoly z protetickej stomatológie. Science 2011; $335-358$.

6. Machoň V.Léčba onemocnění čelistního kloubu. Praha: Grada, 2008: 88.

7. Mračna J. Habitation Thesis. Bratislava: Univerzita Komenského, 1993:107.

8. Machoň V, Lukášová $\mathbf{V}$. Příspěvek k etiologii onemocnění temporomandibulárního kloubu. Prakt Zub Lek 2005; 53 (6): 111-114.

9. Mračna J. Rozdelenie, klinické prejavy a diagnostika ochorení temporomandibulárneho kíbu. Bratisl Med J 1992; 93 (10): 550.

10. Mentelová J, Mračna J, Poruban D. Príspevok k etiológii a rozdeleniu temporomandibulárnych porúch. Stomatológ: Čas Slov Kom Zub Lek 1994; 5 (5): 150-151.

11. Lewit K. Manipulační léčba v myoskeletální medicíne. Praha: Sdělovací technika, s.r.o., 2003: 412.

12. Piekartz H, Hall T. Orofacial manual therapy improves cervical movement impairment associated with headache and features of temporomandibular dysfunction. A randomized controlled trial. http://linkinghub.elsevier.com/retrieve/pii/S1356689X12002718.

13. Nicolakis $\mathbf{P}$, Nicolakis $\mathbf{M}$, Piehslinger $\mathbf{E}$ et al. Relationship between craniomandibular disorders and poor posture. J Craniomandib Prax 2000; 18 (2): 106-112.

14. Olivo SA, Bravo J, Magee DJ et al. The association between head and cervical posture and temporomandibular disorders: a systematic review. J Orofac Pain 2006; 20 (1): 9-23.

15. Michelotti A, De Wijer A, Steenks M, Farella M. Home - exercise regres for the management of non-specific temporomandibular disorders. J Oral Rehab 2005; 11: 779 - 785.

16. Michelotti A, Steenks MH, Farella M, Parisini F, Cimino R, Martina $\mathbf{R}$. The additional value of a home physical therapy regimen versus patient education only for the treatment of myofascial pain of the jaw muscles: short-term results of a randomized clinical trial. J Orofac Pain 2004; 18 (2): 114-125.

17. McNeely M, Armijo OS, Magee D. A systematic review of the effectiveness of physical therapy interventions for temporomandibular disorders. Phys Ther 2006; 86 (5): 710-725.

18. Wijer A, Steenks MH, Leeuw JR et al. Symptoms of the cervical spine in temporomandibular and cervical spine disorders. J Oral Rehab 1996; 23 (11): 742-750.

Received July 7, 2017. Accepted September 25, 2017. 